\title{
Impacts of Cowpea Innovation Platforms in Sustaining TL III Project Gains in Ghana
}

\author{
Julius Yirzagla, Ibrahim K. D. Atokple, Mohammed Haruna, \\ Abdul Razak Mohammed, Desmond Adobaba, \\ Bashiru Haruna, and Benjamin Karikari
}

\begin{abstract}
Over the past decades, farm-level yields of cowpea have remained low $(0.6-0.8 \mathrm{t}$ / ha) compared to what is observed on research fields $(1.8-2.5 \mathrm{t} / \mathrm{ha})$. Lack of farmer access to quality seeds of improved varieties and inappropriate cultural practices are the major factors responsible for the low productivity of the crop. The use of Innovative Platforms (IPs) as a strategy to facilitate farmer access to quality seeds was, therefore, considered under the Tropical Legume (TL) III and USAID Cowpea Outscaling projects in Northern Ghana. The platform activities started in 2016 with a total membership of 100, which increased steadily to 820 by December 2018. The research team of the Council for Scientific and Industrial Research-Savannah Agricultural Research Institute (CSIR-SARI) trained platform members to produce certified seeds to be supplied to target communities, thereby enhancing smallholder farmers' access to improved varieties. A total of 1848 members of the platform were trained in various farm operations. A revolving system was set up in which each farmer group was supplied with improved seed and after harvesting returned the equivalent of seed received to the platform. Having been trained to produce their own seed, members of the platform are selfreliant in acquiring improved seed and are actively engaged in various operations that sustain the gains of the two projects that have been phased out.
\end{abstract}

\section{Keywords}

Revolving system $\cdot$ Stakeholder $\cdot$ Actors $\cdot$ Facilitate access $\cdot$ Strategy

\section{J. Yirzagla $(\triangle)$}

CSIR-SARI, Bawku, Ghana
I. K. D. Atokple · M. Haruna · A. R. Mohammed · D. Adobaba · B. Haruna · B. Karikari
CSIR-SARI, Tamale, Ghana 


\subsection{Introduction}

In northern Ghana, cowpea is the second most important legume crop after groundnut. Its importance in food and soil fertility enhancement cannot be over-emphasized. The potential yield of cowpea is around 1.8-2.5 t/ha but current average yields are in the region of 0.6-0.8 t/ha (SARI 2008). Over the past decades, on-farm yields of cowpea per unit area have remained low (0.6-0.8 t/ha) compared to yields observed on research fields (1.6-2.5 t/ha). Lack of farmer access to high-yielding varieties, biotic and abiotic stresses, and inadequate cultural practices are the major factors responsible for the low productivity of the crop. The Savannah Agricultural Research Institute of the Council for Scientific and Industrial Research (CSIR-SARI), with support from the International Institute of Tropical Agriculture (IITA) has, therefore, developed and released several improved cowpea varieties with the aim of reducing poverty and malnutrition among smallholder farmers in Northern Ghana. Diagnostic surveys, however, show that rural farmers do not have access to the improved varieties. The seed industry in Ghana has been privatized and dealers find it unattractive to open sale outlets in the hinterlands (SARI 2009). Research and extension efforts aimed at developing sustainable cowpea seed production, and delivery systems are, therefore, necessary for increased production and productivity in Ghana.

The use of IPs as a strategy to facilitate farmer access to seeds of improved varieties of cowpea was, therefore, considered under the Bill and Melinda Gates Foundation (BMGF)-funded TL III and the USAID Cowpea Outscaling projects in Northern Ghana. An IP is a stakeholder-led body that brings together representatives of the various actors along crop value chains, including seed actors, to create synergies for diagnosing problems (strengths, weaknesses, and threats within existing legume seed systems), exploring opportunities, investigating/testing, and deploying best-bet solutions. The basic principle of multi-stakeholder platforms (MSPs) is to bring together stakeholders for continuous interactions, responding to emerging seed bottlenecks/demands and lesson learning to ensure that seed and non-seed technology development and dissemination take place for the benefit of target communities. It is made up of a group of individuals (who often represent organizations) with different backgrounds and interests. The members come together to diagnose problems, identify opportunities, and find ways to achieve their goals. They may design and implement activities as a platform, or coordinate activities by individual members.

A typical IP comprises members drawn from both the public and private sectors including public agricultural research institutions (NARS/CGIAR), seed producers (companies and individual entrepreneurs), agro-dealers for seed supplies and complementary inputs, farmers, business organizations, extension service providers, national seed authorities/certifying agencies, representatives of farmers, nongovernmental organizations, faith-based organizations, and other service providers. The interactions in the IP should be motivated by the common interests of members that ensure the development of sustainable seed systems that meet the needs of different actors. 
Under the TL III and USAID partnership, four IPs were established; one each in Navrongo in the Upper East Region, Wa in the Upper West Region, and Walewale and Savelugu in the Northern Region. The aim of establishing these IPs was to bring together stakeholders for continuous interactions and to respond to emerging seed bottlenecks and demands, to ensure that seed and non-seed technology development and dissemination take place to the benefit of target communities. The objective of this write up is to share the experiences especially those of Navrongo IP in facilitating the access of smallholder farmers' to improved cowpea seed.

\subsection{Establishment of the Navrongo IP}

In the year 2011, a rice-based IP was set up in Navrongo in the Upper East Region by CSIR-SARI scientists under the AfricaRISING Project. With the commencement of TL III project activities in 2015, this rice-based IP served as a suitable entry point for mainstreaming cowpea activities to form the cowpea IP. The research team from CSIR-SARI under the TL III project interacted with the executives and the entire membership of the IP during which issues of mainstreaming cowpea activities were discussed. The issues bordered on identification of bottlenecks in the cowpea value chain, identification of the status of seed systems, variety demand, identification and setting joint goals/results, and definition of partners' roles and responsibilities. Other issues discussed included how to carry out activities to strengthen the capacity of platform members, e.g., training in seed production and business management and promoting linkages. Following consensus by members, the idea of incorporating cowpea activities into the existing IP was adopted on 2nd March 2016, which brings the total memberships to 100. The research team met regularly with the executives to review and plan activities. Membership increased steadily between 2016 and 2018 from 100 to 820 (Table 12.1). Some members have been linked to Heritage Seeds Company (HSC), a private seed company that runs an outgrower scheme. As a result, HSC expanded her outgrower scheme from a membership of 208 farmers to 285 within the period (2016-2017). The company has a seed processing unit and now serves as a major off-taker (market access) of the farmers' produce. This linkage, which has increased the demand for cowpea seed (market access) for the platform members, was achieved through the partnership between TL III and the USAID Cowpea Outscaling Project (COSP).

Table 12.1 Membership of Navrongo IP as at December 2018

\begin{tabular}{l|r|l|l|l}
\hline \multirow{2}{*}{ IP members } & Year & 2017 & 2018 & Total \\
\cline { 2 - 5 } & 2016 & 207 & 370 & 370 \\
\hline Men & 50 & 103 & 292 & 292 \\
\hline Women & 42 & 70 & 158 & 158 \\
\hline Youth under 35 & 8 & 380 & 820 & 820 \\
\hline Total & 100 &
\end{tabular}




\subsubsection{Composition, Roles, and Responsibilities of the Platform Members}

The Navrongo platform is composed of farmers, input dealers, transporters and other services, financial institutions, extension agents, research institutions, policy makers, and retailers/consumers. Their roles and responsibilities are stated in Table 12.2.

An executive board was set up comprising the Chairman, Vice Chairman, Secretary, Assistant Secretary, Financial Secretary, Treasurer, and Organizer to oversee the day-to-day activities and administration of the IP. Among others, the board ensures the following:

- Foster dialogue and understanding among stakeholders and provide a space for them to create a common vision and mutual trust.

- Enable partners to identify the bottlenecks hindering innovation and develop solutions beyond what individual actors can achieve alone.

- Create motivation and a feeling of ownership of the solutions that members have developed.

- Facilitate upward communication which enables weaker actors (such as smallscale farmers) to express their views on an equal basis with the more powerful actors.

The individual roles assigned to the board members to achieve these tasks are as follows:

Chairperson Oversees the day-to-day functions and activities of the platform, presides over all meetings and related programs of the platform, and delegates power to other board members when necessary.

Table 12.2 Roles and responsibilities of different stakeholders participating in the platform activities

\begin{tabular}{l|l}
\hline Stakeholders & Roles and responsibilities \\
\hline Farmers & $\begin{array}{l}\text { Problem identification, indigenous knowledge, development of solution, } \\
\text { testing and evaluation of solutions, and adoption of solutions } \\
\text { Timely delivery of quality and affordable inputs/information }\end{array}$ \\
\hline $\begin{array}{l}\text { Input dealers } \\
\text { other services }\end{array}$ & Guarantee timely service provision \\
\hline $\begin{array}{l}\text { Financial } \\
\text { institutions }\end{array}$ & Develop financial products/services that support interventions \\
\hline Extension agents & $\begin{array}{l}\text { Provide information on identification, development, and implementation } \\
\text { of projects }\end{array}$ \\
\hline $\begin{array}{l}\text { Research } \\
\text { institutions }\end{array}$ & $\begin{array}{l}\text { Critical problem analysis, provide solution to the problem, conduct new } \\
\text { research where necessary }\end{array}$ \\
\hline Policy makers & Mobilization of farmers, support formulation of appropriate policies \\
\hline Retailer/consumer & Feedback on perception and consumer behavioral change \\
\hline
\end{tabular}


Vice Chairperson Takes up the duties and functions of the chairman in the absence of the chairman as well as any other duties assigned by the chairman.

Secretary Responsible for record keeping of proceedings of platform meetings and all correspondences of the platform as well as any other duties assigned by the chairman.

Assistant Secretary Takes up the duties and functions of the secretary in his absence as well as any other duties assigned by the chairman.

Financial Secretary Responsible for recording all financial transactions, financial reporting, and correspondence of the platform, as well as any other duties assigned by the chairman.

Treasurer In charge of all financial transactions such as purchases, fund disbursement, reimbursements, record keeping of financial transactions, as well as any other duties assigned by the chairman.

Organizer Liaises with the chairman and other members of the executive to organize meetings and other platform engagements, procure logistics needed for meetings, as well as any other duties assigned by the chairman.

\subsubsection{Platform Activities}

Training Platform members were trained through demonstrations and a community seed production scheme on good agronomic practices (GAPs), integrated pest management (IPM), data collection, etc. Men, women, and young seed technicians (NARS, extensions agents, seed companies, etc.) and outgrowers were trained on foundation and certified seed production. Agro-dealers were trained to market cowpea seed through innovative marketing (sale of small seed packets; $0.25,0.5,1,2,5$, 10 , and $20 \mathrm{~kg}$ ) to increase demand and sale of quality seeds. Through training of trainers' workshops on the use of improved integrated production technologies, management practices were promoted to narrow the yield gaps (between farmer field and research field) to enhance cowpea grain and fodder production. Demonstration activities using the best varieties and IPM options were established to reduce yield losses in cowpea cultivation. Training on improved cowpea storage was organized in partnership with Purdue Improved Crop Storage (PICS) project to promote safe storage of cowpea to reduce insect infestation and damage. Processors were also trained on seed processing (cleaning, sorting, grading, packaging), storage, and marketing. 
Seed Supply CSIR-SARI was responsible for producing breeder and foundation seeds of identified preferred varieties. Together with seed companies, e.g., HSC, CSIR-SARI produced and supplied foundation seeds to community-based organizations to produce quality declared seed and certified seeds to sell in their communities.

Popularizing Improved Cowpea Seed Through the IP, farmer exchange visits were organized to popularize and expose large numbers of stakeholders to improved cowpea production technologies. The media (print and electronic) were engaged to disseminate information on seed of improved cowpea varieties and production technologies. Promotional material such as production guides, brochures, and flyers were produced and distributed to members.

Sensitization Consumers and households were sensitized on nutritional and health benefits of cowpea consumption. Linkages among cowpea farmers, grain buyers, and processors were facilitated. Policymakers and schools were sensitized on feeding programs related to the nutritional and health benefits of cowpea consumption to advocate for the inclusion of more cowpea in the school feeding programs.

Challenges A major challenge was inadequate agricultural extension staff to effectively manage the on-farm demonstrations. Efforts to secure new available markets for farmers' seeds have been a daunting task within the community.

\subsubsection{Facilitation of Platform Activities, Including Meetings}

Platform members met regularly (at least once a month) to discuss the focal areas and identify challenges and opportunities. To enhance stakeholder participation, especially for the weak ones, the platform developed a constitution that governs operations. It has rules, regulations, and by-laws that are followed especially during meetings and other engagements of the members. Ground rules were spelled out during meetings to ensure that participants have equal opportunities to contribute actively to the deliberations (Fig. 12.1). This was necessary to minimize marginalization of the weak especially women and the youth.

During decision-making processes, especially pertaining to problem-solving, platform members decide how to solve the problems or take advantage of already identified opportunities and when solutions are identified, they are tested and adapted to ensure that they are effective. The capacities of different actors were strengthened to enable them to solve their own problems. To ensure that platform operations are effective, two project-monitoring reports and quarterly reports were submitted to the project coordination unit at CSIR-SARI. 


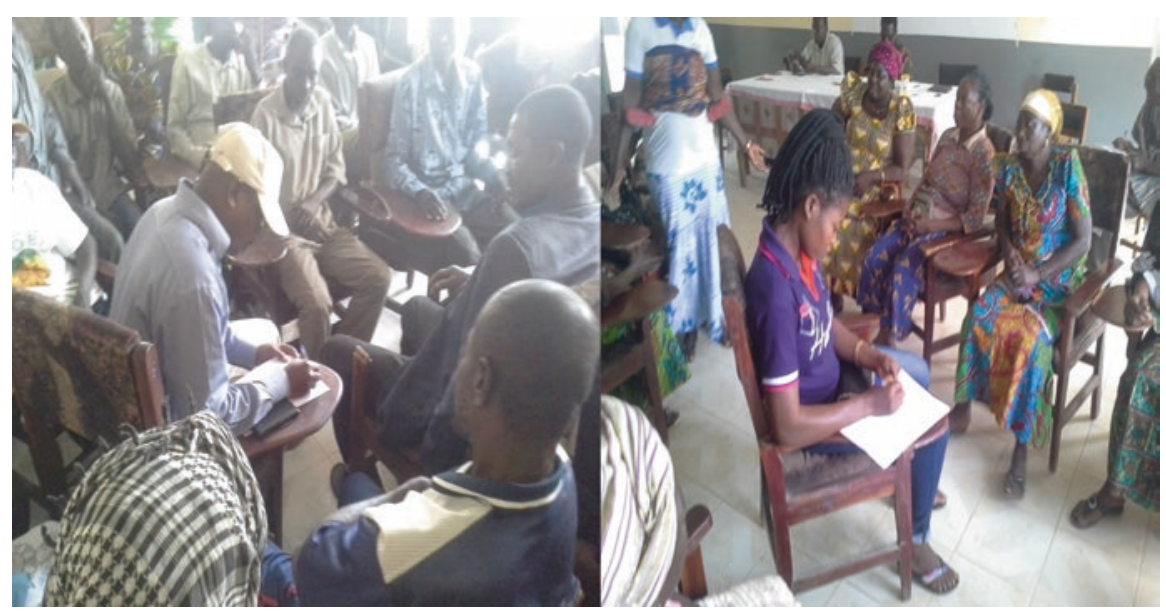

Fig. 12.1 Meeting of the Council for Scientific and Industrial Research-Savanna Agriculture Research Institute

\subsubsection{Achievements of the Platform}

Access to Knowledge and Farm Advisory Services In collaboration with the USAID-COSP Project, agricultural extension agents (AEAs) in the IP were trained on pre- and postharvest operations such as quality seed production, GAPs, postharvest handling, pest management and data collection, safe use of agrochemicals, proper identification of maturity periods, and timely harvesting of cowpea using the demonstration protocols. These extension agents in turn trained other platform members (farmers, input dealers, and processors) in the various operations. In all, 346 farmers were trained in 2016, 722 input dealers in 2017, and 1848 processors in 2018 , in the various farm operations (Table 12.3). Another area of access to knowledge and farm advisory services was through demonstration fields which were used as a strategy to keep the stakeholders abreast of cowpea production technologies. These included GAPs, IPM, PICS storage, and nutritional issues. The practical demonstration training covered all production stages: land preparation, planting, crop management, harvesting, and storage. The quality seed production training was carried out with resource persons from the Ghana Seed Inspection Directorate of the Ministry of Food and Agriculture (MOFA).

In addition, radio jingles developed by Farm Radio International (FRI), in collaboration with local FM stations, also offered access to knowledge and farm advisory services on cowpea storage in local languages (Dagbanli and Dagare), and promoted knowledge of improved cowpea storage. The FRI radio program helped to sensitize households on nutritional and health benefits of cowpea consumption, reaching out to over 14,000 beneficiaries. Sensitization of farmers on improved high-yielding varieties of cowpea for increased productivity of smallholder 


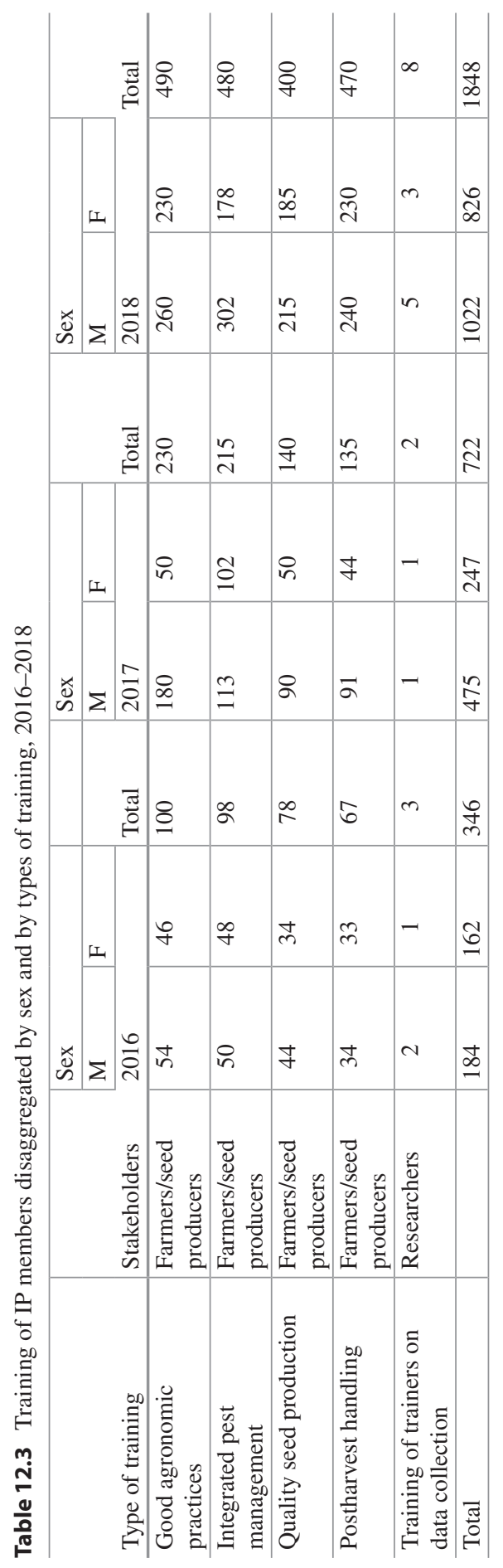


households was promoted through field days and mass media engagement. Field days were carried out at least two times in each participating community. The media: Ghana News Agency (GNA), Ghana Broadcasting Corporation (GBC), and FRI were engaged to popularize the improved cowpea varieties. The training opportunity for platform members, field days, and media engagement have enhanced their access to knowledge and farm advisory services (Quarterly bulletin 2017).

Access to Improved Seed and Other Inputs To facilitate access to improved seed and other inputs, foundation seed and quality declared seeds were supplied by the SARI research team through MOFA to platform members for the production of grain and quality declared seed. To ensure sustainability, plans are underway for SARI to supply the foundation seed to seed companies such as HSC and members of the platform who will sell certified seed to farmers for the production of QDS. Improved farmer-preferred, high-yielding pest and disease-tolerant varieties of cowpea identified and produced by CSIR-SARI were Songotra, Apagbaala, Padituya, Zaayura, Wang Kae, Kirkhouse Benga, Difeele, and Zaayurapali. Through training of trainer (ToT) workshops by extension staff of MoFA, the capacity of male and female farmers was strengthened in the production of cowpea seeds. Community seed fields were established alongside demonstration fields that showcased GAPs of cowpea production, spraying regimes, and use of host-plant resistance to control Striga gesnerioides in the target communities. Farmer Field Schools (FFSs) were used to train farmers on these technologies. With the increased (45\%) availability and awareness of seeds of improved cowpea varieties, the overall acreage grown to improved seed by farmers increased by $37 \%$ in the target communities. This has offered opportunity even to non-member farmers to access seed through platform members. This has enhanced smallholder farmer access to improved cowpea seeds over time including non-members of the IP (Table 12.4). To disseminate the improved varieties widely, a revolving system was set up in which each farmer group was supplied with improved seed the equivalent of which would be returned to the platform after harvesting. In the following year, new groups were identified for the revolving system. Each community mobilized agents to follow-up for seed recovery. This arrangement ensures an average supply of $900 \mathrm{~kg}$ annually to the platform. Having been trained to produce their own seed, members of the

Table 12.4 Farmers' access to seed of improved cowpea varieties and total area grown to improved cowpea during the 2016, 2017, and 2018 cropping seasons

\begin{tabular}{|c|c|c|c|c|c|}
\hline & \multicolumn{4}{|l|}{ Year } & \multirow[b]{2}{*}{ Total } \\
\hline & & 2016 & 2017 & 2018 & \\
\hline & \multicolumn{4}{|l|}{ Number of farmers } & \\
\hline Variable & No. & 100 & 230 & 490 & 820 \\
\hline \multirow[t]{2}{*}{ Access to improved seed } & Before IP membership & 15 & 50 & 200 & 265 \\
\hline & After IP membership & 85 & 180 & 290 & 555 \\
\hline \multirow[t]{2}{*}{ Land area grown to improved seed } & Before IP membership & 10 & 76 & 150 & 236 \\
\hline & After IP membership & 90 & 154 & 340 & 584 \\
\hline
\end{tabular}

$N$ number of respondents 
platform were self-reliant in acquiring improved seed and were actively engaged in various operations that sustain the gains of the two projects that have been phased out (DGIC 2001).

Access to New Markets and Finance Services To expand market access for platform members, SeedPAG established linkages with some agro-dealers (e.g., Simple Prince Enterprise in Bolgatanga) which served as off-takers of quality declared and certified seeds produced by members of the platform. SeedPAG also contracted the Plant Protection and Regulator Services Directorate (PPRSD) of MoFA to manufacture and supply 16,050 pieces of the packaging bags under the innovative marketing scheme to create demand for improved seed. Besides agro-input dealers, open market, community members, and seed companies are the major off-takers of the cowpea produced by members. An average of $930 \mathrm{~kg}$ (representing 50\%) of seeds produced by platform members was sold in small packs $(0.5,1,2,5 \mathrm{~kg})$ in 2016 with the percentage progressing to $100 \%$ by the end of project (2018). Within this period, almost 180 small packs of various sizes were sold, which benefitted more than 300 farmers from the innovative marketing scheme. This increased affordability and expanded the access of smallholder farmers to improved quality of cowpea seed. Radio broadcasts, agricultural shows and seed fairs were employed to market seed in small packets. The inclusion of a financial institution in the membership of the platform enhanced the access of members to credit facilities from financial institutions. This afforded some members the opportunity to secure credit to expand their cowpea fields for increased production and productivity.

Social Assets, Gender Equality, and Youth Other areas of achievement include areas of social assets, gender equality, and youth participation. Through sensitization workshops organized for platform members and other educational campaigns and for a women farmers in the platform now have equal access to agricultural lands and other social assets. Women hitherto did not contribute to discussions at gatherings even if they had useful contributions to make. It was considered disrespectful on the part of women to make a submission in a gathering involving both sexes, especially in the presence of their spouses. The youth as well could not make any submission at meetings except through an adult member. These were some of the social restrictions that marginalized women and the youth in many communities in northern Ghana. As a result of their membership of the IP the social status of women and youth has improved significantly; and they now have equal opportunities to social assets and other services. This became obvious when some women leaders in the IP gave a good account of themselves, earning a great deal of respect from their male counterparts.

A major challenge of the IP is that some of the stakeholders on the platforms are not well organized unlike the farmers who are well organized. The processors, for instance, are supposed to be organized in groups. Plans are, however, far advanced 
to ensure that all stakeholders on the platforms are as organized as the farmer groups. Despite this challenge, members of the platform perceive the performance of the platform as laudable and are committed to the rules and by-laws governing its operations.

The success of the Navrongo IP depends largely on the harmonious interaction among the stakeholders. Sustainability measures have, therefore, been put in place to ensure the IP remains vibrant after TL III and USAID projects phase out. A number of lessons have been instilled in the members including, but not limited to the following:

- The need for well-defined and coordinated roles for all stakeholders.

- Recognition of synergy by all actors and their interest to benefit from it.

- Trust, confidence, and understanding among stakeholders.

- Good leadership and facilitation skills by the IP stakeholders and the facilitating institution and focal person(s).

- Facilitating and managing perceptions, competing interests, risks, availability, and access to resources among the diverse social and economic interests of stakeholders.

- Time and availability of individuals and groups.

- Reliable information, communication, documentation, and learning and sharing of best practices.

\subsection{Reflections on the Process}

The platforms created opportunities for research to be demand-driven as they identified and presented researchers with critical issues for investigation. This benefitted the platform members and the community as a whole and has afforded platform members and the community in general the opportunity to make informed decisions regarding their operations, thus ensuring joint learning and cooperation among diverse actors to solve problems and reduce uncertainties. The platform facilitated the acquisition of agro-input for the members. During the farming season, subsidized fertilizer is released from the various district offices of MoFA to the general public (farmers) for their farm operations. These fertilizers are usually more affordable than those sold on the open market, resulting in a rush and competition for their procurement. Individuals, therefore, find it difficult to secure these low-priced fertilizers and eventually have to buy the more expensive ones in the open market. However, with the assistance and influence of agricultural extension agents (AEAs) from MoFA in the platform, bulk procurement of these inputs is facilitated for platform members. Farmers in the platform are, therefore, able to improve their agricultural production and productivity. With good representation of various stakeholders in the platform, members are better informed on issues pertaining to the agricultural sector. 
Having been trained to produce their own seeds, members of the platform are self-reliant in acquiring improved seed and are actively engaged in various operations that sustain the gains of the two projects that have been phased out.

\subsection{Areas to Focus on in the Future}

There is the need to explore opportunities for more off-takers to create demand for greater market access in future interventions. Efforts will be made to promote value addition to increase market demand. Issues of platform sustainability will be given priority attention by exploring avenues to source funds to run the activities of the platform. There is the need also for a meeting of partners, e.g., seed companies, MoFA, and registered seed producers to plan linkages between registered seed producers (men, women, and youths) and seed certification agencies. Organizational capacity development of producers and other community-based organizations needs to be developed to enable small-scale farmers to collectively act and innovate. The sure way to achieve this is to facilitate linkages among all the stakeholders. It must be recognized that focus group discussion is necessary to provide a forum for direct dialogue as well as participatory approaches to facilitate ownership of the platform. In addition, appropriate dissemination pathways are needed to catalyze entrepreneurship and market access. To improve performance, there is the need for functional learning to learn lessons and share experiences.

\subsection{Lessons Learned}

The IP has enhanced cowpea productivity and cowpea market demand among smallholder farmers. Production and supply of foundation, certified, and quality declared seed of released varieties have been catalyzed. The performance of popular and newly released varieties has been improved through sustainable intensification of production and postharvest systems. Innovative seed marketing targeted at women and the poor has been catalyzed, and professionalized. Awareness is created through multimedia systems (demonstrations, field days, ICT, resources manuals, TV/radios, and local and international newspapers) leading to food and nutrition security, and increased incomes, thus increasing the welfare of the target societies.

\section{References}

Directorate General for International Co-operation (DGIC) (2001) In: Raemaekers RH (ed) Crop production in Tropical Africa. DGIC, Brussels, Belgium, pp 335-338

Savanna Agricultural Research Institute (SARI) (2008) Annual Report

Savanna Agricultural Research Institute (SARI) (2009) Annual Report

Seventh Bulletin of the quarterly publication of Tropical Legumes III (TL III) project (2017) 
Open Access This chapter is licensed under the terms of the Creative Commons Attribution 4.0 International License (http://creativecommons.org/licenses/by/4.0/), which permits use, sharing, adaptation, distribution and reproduction in any medium or format, as long as you give appropriate credit to the original author(s) and the source, provide a link to the Creative Commons license and indicate if changes were made.

The images or other third party material in this chapter are included in the chapter's Creative Commons license, unless indicated otherwise in a credit line to the material. If material is not included in the chapter's Creative Commons license and your intended use is not permitted by statutory regulation or exceeds the permitted use, you will need to obtain permission directly from the copyright holder. 